Article

\title{
Optimization of the Changing Phase Fluid in a Carnot Type Engine for the Recovery of a Given Waste Heat Source
}

\section{Mathilde Blaise ${ }^{1,2, *}$, Michel Feidt ${ }^{1}$ and Denis Maillet ${ }^{1}$}

1 Laboratoire d'Énergétique et de Mécanique Théorique et Appliquée, UMR 7563, Université de Lorraine, 54518 Vandoeuvre-lès-Nancy, France; E-Mails: michel.feidt@univ-lorraine.fr (M.F.); denis.maillet@univ-lorraine.fr (D.M.)

2 Agence de l'Environnement et de la Maîtrise de l'Energie (ADEME), 20, avenue du Grésillé-BP 90406, 49004 Angers Cedex 01, France

* Author to whom correspondence should be addressed; E-Mail: mathilde.blaise@univ-lorraine.fr; Tel.: +33-383-595-554.

Academic Editor: Kevin H. Knuth

Received: 10 July 2015 / Accepted: 27 July 2015 / Published: 31 July 2015

\begin{abstract}
A Carnot type engine with a changing phase during the heating and the cooling is modeled with its thermal contact with the heat source. In a first optimization, the optimal high temperature of the cycle is determined to maximize the power output. The temperature and the mass flow rate of the heat source are given. This does not take into account the converter internal fluid and its mass flow rate. It is an exogenous optimization of the converter. In a second optimization, the endogenous optimization, the isothermal heating corresponds only to the vaporization of the selected fluid. The maximization of the power output gives the optimal vaporization temperature of the cycled fluid. Using these two optima allows connecting the temperature of the heat source to the working fluid used. For a given temperature level, mass flow rate and composition of the waste heat to recover, an optimal fluid and its temperature of vaporization are deduced. The optimal conditions size also the internal mass flow rate and the compression ratio (pump size). The optimum corresponds to the maximum of the power output and must be combined with the environmental fluid impact and the technological constraints.
\end{abstract}

Keywords: optimization; working fluid; Carnot engine; waste heat recovery 


\section{Introduction}

The first thermal model applied to an engine was developed by Carnot [1]. He describes a series of ideal thermodynamic transformations to convert heat into mechanical energy. The main features of his concept are the isothermal heating and the isothermal cooling. He chooses a vapor engine with a phase change and an air piston engine as examples. Carnot introduces a fundamental efficiency limit for converting thermal energy into mechanical energy. The maximal efficiency of a Carnot engine is given by the expression $\eta_{C}=1-T_{L S} / T_{H S}$, where $T_{H S}$ and $T_{L S}$ are, respectively, the temperature of the heat source and the heat sink. He clearly states that the nature of the fluid and its state do not affect this theoretical limit. However, in this approach, the working fluid is supposed to be at the heat source temperature during the isothermal expansion and at the cold sink temperature during the isothermal compression. These assumptions require thermal equilibrium between the working fluid and the heat source or sink during the thermal transfers (Figure 1a). These assumptions imply infinitely slow transformations and, under these conditions, zero power output.

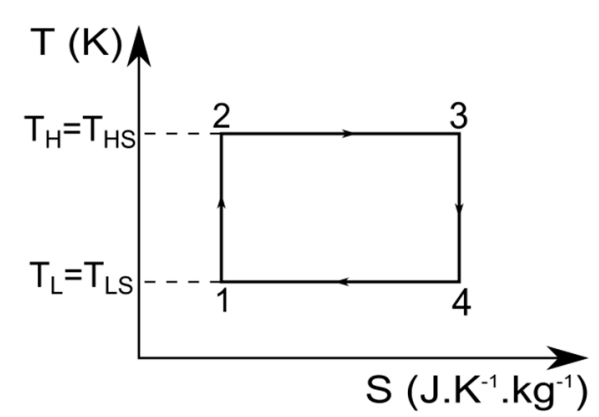

(a)

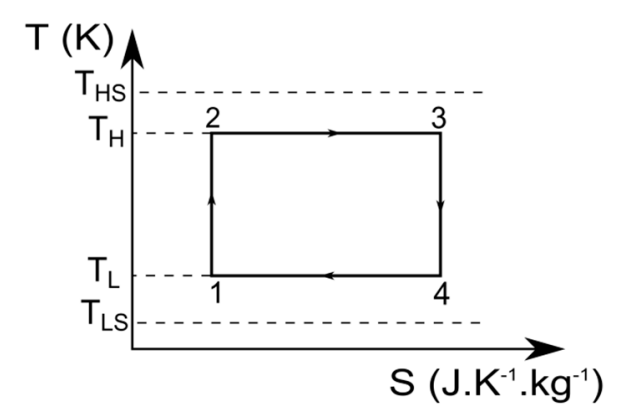

(b)

Figure 1. Entropy diagram of a Carnot cycle; (a) for an ideal Carnot engine; (b) for an ideal Carnot engine with thermal transfer consideration.

Curzon and Ahlborn consider another fundamental limitation on efficiency that is caused by the rate at which heat can be exchanged between the working fluid and the heat reservoirs [2] (Figure 1b). They introduce an efficiency of the Carnot engine at maximum power output, which is given by the expression $\eta_{C N C A}=1-\sqrt{T_{L S} / T_{H S}}$. Historically, this theoretical limitation was introduced by Novikov [3] and, simultaneously, by Chambadal in France [4]. Some recent articles [5,6] refer to an older paper of Yvon [7]. In this paper, Yvon introduced the optimal high temperature, which maximizes the mechanical power output as if it was a widely known and accepted result. These considerations have led to Finite Time Thermodynamics [8]. The Carnot ideal engine was extended to an irreversible one with a finite heat source and heat sink reservoirs (Figure 2) [9-12]. This system approach allows sizing an optimal Carnot engine independently of the working fluid and its state. The external fluids (heat source and cold sink) are considered limiting. This optimization is described as exogenous, that is, external to the converter. Finite Time Thermodynamics evolved to Optimal Thermodynamics in Finite Physical Dimensions [13]. 


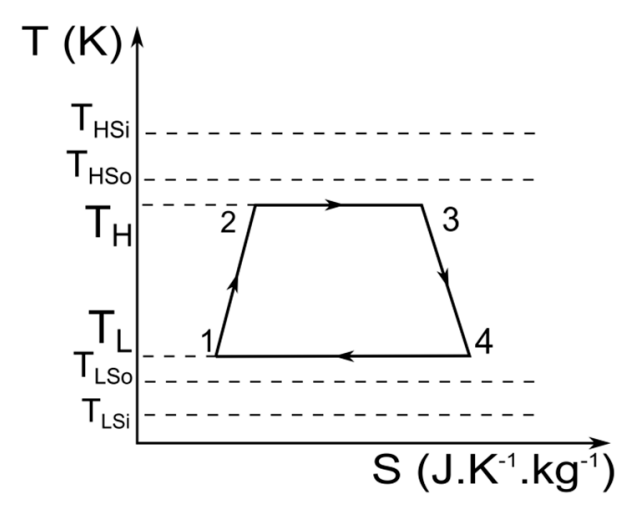

Figure 2. Entropy diagram of an irreversible Carnot engine with finite heat source and heat sink reservoirs.

The working fluid choice is important and has been the subject of many articles, particularly for Rankine cycles [14-20]. The ideal working fluid must have good thermo-physical properties, but also adequate chemical stability in the desired temperature range. The fluid selection considerably affects the operating conditions, the environment impact, and the cost. In practice, a fluid that satisfies all the ideal fluid criteria does not exist. In this article, an endoreversible changing phase Carnot engine is studied, as shown in Figure 3. The vaporization and the condensation at a constant temperature are means to implement a Carnot engine. There is no technical description of a specific Carnot type engine in the present work; only a proposition of a general design process. It can be adapted to the Rankine engine and also to other technologies operating according to a cycle similar to the Carnot cycle [21].

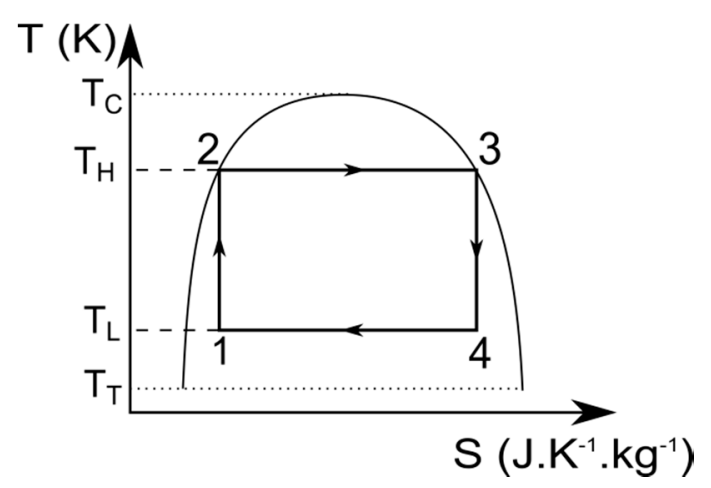

Figure 3. Changing phase Carnot engine.

The model used is an endoreversible engine (Figure 4). The hot fluid enters at temperature $T_{H S i}$ and exits at temperature $T_{H S o}$. The cold fluid enters at temperature $T_{L S i}$ and exits at temperature $T_{L S o}$. Heat transfer is taken into account here at the hot side only and not at the cold side. This simplifying assumption allows avoiding the temperature gap at the cold sink. It is equivalent to assuming known the condensation temperature or the condensation pressure in the condenser. Both physical quantities are strongly related to the environment. That is why two cases are covered in this work. Firstly, the low temperature is imposed equal to the ambient temperature $T_{0}$. This corresponds to assuming that $T_{L}=T_{L S i}=T_{L S o}=T_{0}$, which corresponds to Chambadal model [4]. Secondly, the low pressure is imposed equal to the atmospheric pressure. The cycle is optimized to maximize the mechanical power output. The parameters are the fluid characteristics, which are the temperature at the critical point, the 
temperature at the triple point, and the latent heat of vaporization at the triple point. An identified expression of the latent heat of vaporization is given depending on the parameters and on the variable $T_{H}$, the temperature of vaporization. This optimization is described as endogenous, that is, internal to the converter and independent of the heat source.

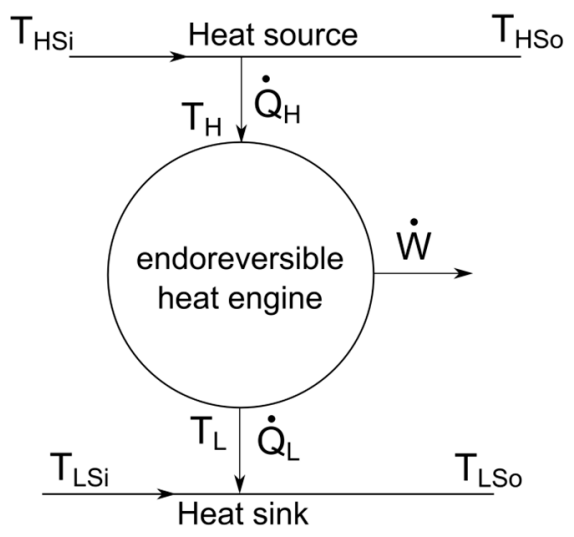

Figure 4. Endoreversible heat engine.

The last specific feature of this work is a way of linking exogenous and endogenous optima. This allows determining, for a given heat source temperature level and mass flow rate, the adapted working fluid, its optimal temperature of vaporization, and its optimal mass flow rate. The chosen criterion is thermodynamic. This optimum constitutes a tool for choosing the working fluid, even if it cannot be considered independently of environmental, technological, and economic criterions.

\section{General Endoreversible Carnot Engine Model}

\subsection{Assumptions and Balances}

The engine diagram is given in Figure 4. The heat source is considered as a finite heat reservoir, the hot fluid enters at $T_{H S i}$ and exits at $T_{H S o}$. Symmetrically, the cold source is considered as a finite heat reservoir, the cold fluid enters at $T_{L S i}$ and exits at $T_{L S o}$. The cycled fluid is at $T_{H}$ at the hot side and at $T_{L}$ at the cold side. To simplify, the assumption is added that $T_{L}$ is known. Thus, $T_{L}$ is a parameter as mentioned in Section 1. The steady state hypothesis is used so the entering heat rate is $\dot{Q}_{H}$, the outgoing heat rate is $\dot{Q}_{L}$ and the outgoing mechanical power is $\dot{W}$. The endoreversible case is considered, which corresponds to the case where the internal entropy production of the converter is neglected. The thermodynamic convention is used: each quantity going into the system is positive and the quantity going out is negative.

The energy balance is:

$$
-\dot{W}=\dot{Q}_{H}+\dot{Q}_{L}
$$

The entropy balance of the converter in the endoreversible case is:

$$
\frac{\dot{Q}_{H}}{T_{H}}+\frac{\dot{Q}_{L}}{T_{L}}=0
$$




\subsection{Exogenous Optimization}

The results of the general optimization are taken here for a Carnot engine. We can express the entering heat rate as:

$$
\dot{Q}_{H}=\dot{C}_{H}\left(T_{H S i}-T_{H S o}\right)
$$

$\dot{C}_{H}$ is the heat source calorific rate:

$$
\dot{C}_{H}=\dot{m}_{H S} c_{p_{H S}}
$$

$\dot{m}_{H S}$ is the mass flow rate of the heat source and $c_{p_{H S}}$ is the calorific capacity, assumed not variable during the heat transfer.

The exchanger is supposed to be an ideal one, so the output temperature is equal to the high temperature of the internal fluid. The exchanger effectiveness is supposed to equal 1 . We can write:

$$
\dot{Q}_{H}=\dot{C}_{H}\left(T_{H S i}-T_{H}\right)
$$

Injecting (2) and (3) in (1), the power output is given by:

$$
-\dot{W}=\dot{C}_{H}\left(T_{H S i}-T_{H}\right)\left(1-\frac{T_{L}}{T_{H}}\right)
$$

For $\dot{C}_{H}, T_{H S i}$, and $T_{L}$ given, the optimal high temperature at maximum power output is the solution of $d(-\dot{W}) / d T_{H}=0[5]$ :

$$
T_{H_{\text {opt }}}^{\text {exo }}=\sqrt{T_{L} T_{H S i}}
$$

The corresponding maximum power output is:

$$
-\dot{W}^{\text {exo }}=\dot{C}_{H}\left(\sqrt{T_{H S i}}-\sqrt{T_{L}}\right)^{2}
$$

The entering heat rate becomes:

$$
\dot{Q}_{H}^{e x o}=\dot{C}_{H} \sqrt{T_{H S i}}\left(\sqrt{T_{H S i}}-\sqrt{T_{L}}\right)
$$

The outgoing heat rate is:

$$
\dot{Q}_{L}^{\text {exo }}=\dot{C}_{H} \sqrt{T_{L}}\left(\sqrt{T_{L}}-\sqrt{T_{H S i}}\right)
$$

These three energy flows (Equations (8) to (10)) can be made dimensionless:

$$
T_{H S i}=t_{h s i} T_{0} ; T_{L}=t_{l} T_{0} ; \dot{Q}=\dot{q} \dot{C}_{H} T_{0} ; \dot{W}=\dot{w} \dot{C}_{H} T_{0}
$$

The expression of the optimal dimensionless temperature is:

$$
t_{h_{\text {opt }}}^{\text {exo }}=\sqrt{t_{l} t_{h s i}}
$$

The expression of the dimensionless power output is:

$$
-w^{\text {exo }}=\left(\sqrt{t_{h s i}}-\sqrt{t_{l}}\right)^{2}
$$

The dimensionless entering heat rate is:

$$
q_{h}^{e x o}=\sqrt{t_{h s i}}\left(\sqrt{t_{h s i}}-\sqrt{t_{l}}\right)
$$

The dimensionless outgoing heat rate is: 


$$
q_{l}^{\text {exo }}=\sqrt{t_{l}}\left(\sqrt{t_{l}}-\sqrt{t_{h s i}}\right)
$$

The optimal dimensionless temperature, the dimensionless power output, the dimensionless entering heat rate, and the dimensionless outgoing heat rate are plotted as a function of $t_{h s i}$ in Figure 5a. The low temperature is fixed at an ambient temperature, assumed equal to $300 \mathrm{~K}$. This choice of ambient temperature must be adapted to the considered environment.

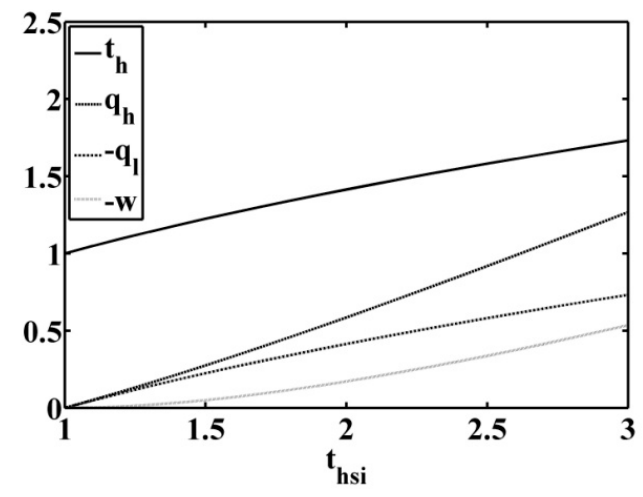

(a)

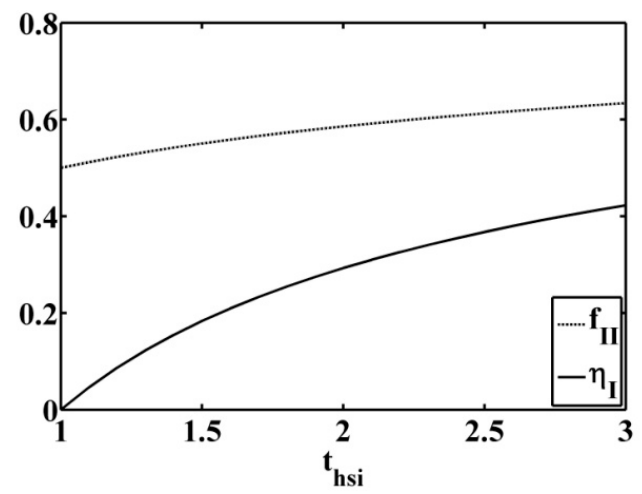

(b)

Figure 5. (a) Optimal high temperature, power output, entering heat flow rate and outgoing heat flow rate; (b) first law and second law efficiency behavior; for inlet temperature heat source variable and low temperature imposed equal to $T_{0}=300 \mathrm{~K}$.

The first law efficiency corresponding to the power output divided by the entering heat rate is:

$$
\eta_{I}=\frac{-\dot{W}}{\dot{Q}_{H}}=1-\sqrt{\frac{T_{L}}{T_{H S i}}}
$$

The second law quality factor is:

$$
f_{I I}=\frac{\eta_{I}}{1-\frac{T_{L}}{T_{H S i}}}=\frac{1}{1+\sqrt{\frac{T_{L}}{T_{H S i}}}}
$$

The evolution of the first law efficiency and the second law quality factor is given in Figure $5 \mathrm{~b}$ for a Chambadal model $\left(T_{L}=T_{0}\right)[4]$.

\section{Changing Phase Carnot Engine}

\subsection{Evolution of the Latent Heat of Vaporization with the Temperature}

In this section, a changing phase Carnot engine is considered (Figure 3). The transformation heat is supposed to be the latent heat of vaporization at $T_{H}$. It imposes knowing the way that the latent heat of vaporization varies with $T_{H}$. For a given fluid, the latent heat of vaporization is equal to zero at the critical temperature $T_{C}$ and is supposed to be known at the temperature of the triple point $T_{T}$ :

$$
L\left(T_{T}\right)=L_{T_{T}}
$$

The latent heat of vaporization decrease with an increased of temperature can be modeled in a reasonable way using the following analytical equation: 


$$
L(T)=L_{T_{T}}\left(\frac{T_{C}-T}{T_{C}-T_{T}}\right)^{\frac{1}{n}}
$$

For a linear approximation of the latent heat of vaporization, $n$ is equal to 1 . In this approximation, if the saturation dome of the considered fluid is symmetric, the latent heat of vaporization is shown in Figure 6. The increase of the $\mathrm{n}$ value is also shown in the figure, in this case there is an adapted $\mathrm{n}$ value of between 2 and 3. A large selection of fluids with their main properties is given in Table 1. The properties are taken from the software Refprop. The considered fluids are chosen because their temperatures at the triple point are below $300 \mathrm{~K}$. They are also chosen for their variable critical temperatures, ranked in increasing order, in the table. The knowledge of the latent heat of vaporization variation with temperature for each fluid allows an optimal estimation of $n$ by a least square regression, of which output is plotted together with the reference data. The comparisons for inorganic pure fluids are given in Figure 7. Figure 7a is the latent heat of vaporization of water and Figure $7 \mathrm{~b}$ that of ammonia. A large selection of hydrocarbons is represented in Figure 8 ((a) butane, (b) isobutene, (c) cyclopentane, and (d) cyclohexane) and in Figure 9 ((a) propane, (b) benzene, (c) decane, (d) toluene, and (e) acetone). Halogenated hydrocarbons are also considered. Some HCFC (HydroChloroFluoroCarbons) are given in Figure 10 ((a) R22 and (b) R123) and some HFC (HydroFluoroCarbons) are given in Figure 11 ((a) R32, (b) R125, (c) R134a, (d) R143a, and (e) R152a) and Figure 12 ((a) R227ea and (b) R245fa). Approximation (21) with different $n$ values is acceptable for all of the selected fluids. The relative bias is given by:

$$
e_{L}\left(T_{H}\right)=\frac{\left|L_{\text {approxim }}\left(T_{H}\right)-L_{\text {experimental }}\left(T_{H}\right)\right|}{L_{\text {approxim }}\left(T_{H}\right)}
$$

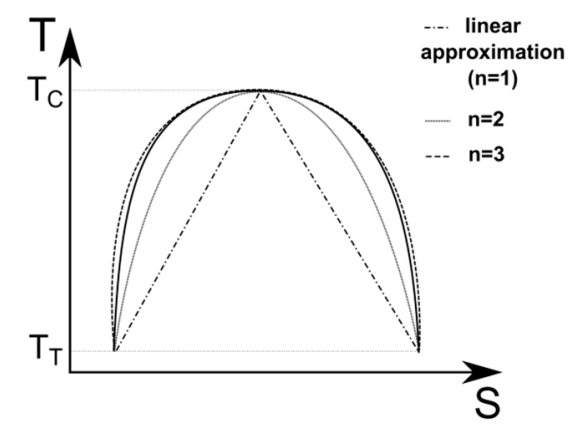

Figure 6. Approximation of the latent heat of vaporization for a symmetric dome of saturation.

Table 1. Properties of the fluid selection.

\begin{tabular}{cccccccc}
\hline \multirow{2}{*}{ Substance } & \multirow{2}{*}{$\begin{array}{c}\text { Molecular } \\
\text { formula }\end{array}$} & \multicolumn{3}{c}{ Physical data } & \multicolumn{3}{c}{ Approximation data } \\
\cline { 3 - 7 } & $\boldsymbol{T}_{\boldsymbol{C}}(\mathbf{K})$ & $\boldsymbol{T}_{\boldsymbol{C}}(\mathbf{K})$ & $\boldsymbol{L}_{\boldsymbol{T}_{\boldsymbol{T}}}(\mathbf{J} / \mathbf{k g})$ & $\boldsymbol{n}$ value & $\boldsymbol{e}_{\boldsymbol{L}_{\boldsymbol{m a x}}}(\boldsymbol{\%})$ & $\boldsymbol{e}_{\boldsymbol{L}_{\boldsymbol{a v e}}}(\boldsymbol{\%})$ \\
\hline $\mathrm{R} 125$ & $\mathrm{CHF}_{3} C F_{3}$ & 339 & 173 & $1.90 \times 10^{5}$ & 2.6 & 2.2 & 0.5 \\
R143a & $\mathrm{C}_{2} H_{2} F_{3}$ & 346 & 161 & $2.67 \times 10^{5}$ & 2.6 & 1.6 & 0.4 \\
R32 & $\mathrm{CH}_{2} F_{2}$ & 351 & 136 & $4.63 \times 10^{5}$ & 2.6 & 2.7 & 0.5 \\
R22 & $\mathrm{CHClF}_{2}$ & 369 & 116 & $3.03 \times 10^{5}$ & 2.5 & 2.2 & 1.1 \\
propane & $\mathrm{C}_{3} H_{8}$ & 370 & 86 & $5.63 \times 10^{5}$ & 2.6 & 1.7 & 1 \\
R134a & $\mathrm{C}_{2} \mathrm{H}_{2} F_{4}$ & 374 & 170 & $2.63 \times 10^{5}$ & 2.5 & 3.0 & 0.6 \\
R227ea & $\mathrm{C}_{3} \mathrm{HF}_{7}$ & 375 & 146 & $1.75 \times 10^{5}$ & 2.5 & 2.3 & 1.6 \\
R152a & $\mathrm{C}_{2} \mathrm{H}_{4} F_{2}$ & 386 & 155 & $4.06 \times 10^{5}$ & 2.5 & 1.7 & 0.6 \\
\hline
\end{tabular}


Table 1. Cont.

\begin{tabular}{|c|c|c|c|c|c|c|c|}
\hline \multirow{2}{*}{ Substance } & \multirow{2}{*}{$\begin{array}{c}\text { Molecular } \\
\text { formula }\end{array}$} & \multicolumn{3}{|c|}{ Physical data } & \multicolumn{3}{|c|}{ Approximation data } \\
\hline & & $T_{C}(\mathbf{K})$ & $T_{C}(\mathbf{K})$ & $L_{T_{T}}(\mathbf{J} / \mathbf{k g})$ & $n$ value & $e_{L_{\max }}(\%)$ & $e_{L_{a v e}}(\%)$ \\
\hline ammonia & $\mathrm{NH}_{3}$ & 405 & 195 & $1.48 \times 10^{6}$ & 2.6 & 4.4 & 1.4 \\
\hline isobutane & $\mathrm{C}_{4} \mathrm{H}_{10}$ & 408 & 114 & $4.81 \times 10^{5}$ & 2.6 & 1.5 & 0.7 \\
\hline butane & $\mathrm{C}_{4} \mathrm{H}_{10}$ & 425 & 135 & $4.96 \times 10^{5}$ & 2.6 & 1.3 & 0.7 \\
\hline R245fa & $C_{3} H_{3} F_{5}$ & 427 & 171 & $2.59 \times 10^{5}$ & 2.3 & 16 & 3 \\
\hline $\mathrm{R} 123$ & $\mathrm{C}_{2} \mathrm{HCl}_{2} \mathrm{~F}_{3}$ & 457 & 166 & $2.24 \times 10^{5}$ & 2.4 & 8.9 & 1.8 \\
\hline acetone & $\mathrm{CH}_{3} \mathrm{COCH}_{3}$ & 508 & 179 & $6.49 \times 10^{5}$ & 2.4 & 5 & 1 \\
\hline cyclopentane & $C_{5} H_{10}$ & 512 & 180 & $4.87 \times 10^{5}$ & 2.5 & 25 & 2.2 \\
\hline cyclohexane & $\mathrm{C}_{6} \mathrm{H}_{12}$ & 554 & 279 & $4.04 \times 10^{5}$ & 2.5 & 1.5 & 0.7 \\
\hline benzene & $\mathrm{C}_{6} \mathrm{H}_{6}$ & 562 & 279 & $4.48 \times 10^{5}$ & 2.5 & 1.2 & 0.6 \\
\hline toluene & $\mathrm{C}_{7} \mathrm{H}_{8}$ & 592 & 178 & $4.92 \times 10^{5}$ & 2.3 & 5.8 & 2.2 \\
\hline decane & $\mathrm{C}_{10} \mathrm{H}_{22}$ & 618 & 244 & $3.93 \times 10^{5}$ & 2.3 & 2.7 & 1.4 \\
\hline water & $\mathrm{H}_{2} \mathrm{O}$ & 647 & 273 & $2.50 \times 10^{6}$ & 2.9 & 12 & 1.7 \\
\hline
\end{tabular}

The maximum average bias is $3 \%$ and relative to $\mathrm{R} 245 \mathrm{fa}$, which is acceptable (Table 1). The maximum relative error is for the cyclopentane (25\%), which is high but is very close to the critical point value. At this point, the latent heat of vaporization is close to zero, so a small absolute error becomes a very large relative error. The other maximum relative bias has the same cause.

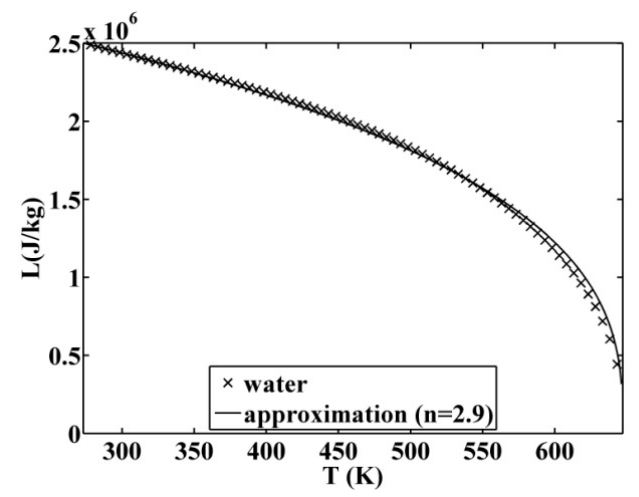

(a)

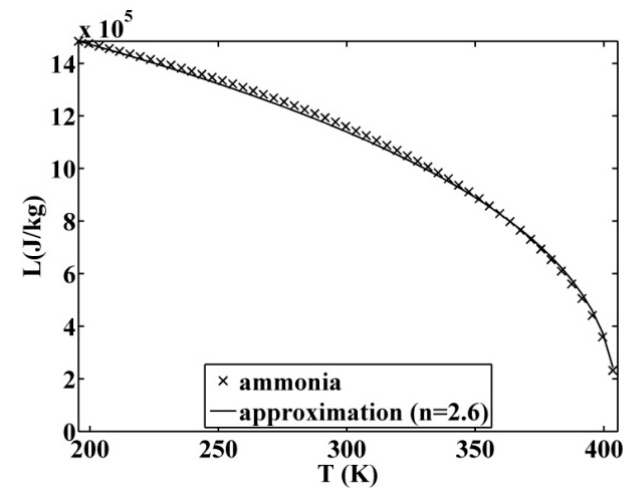

(b)

Figure 7. Approximated latent heat of vaporization for (a) water and (b) ammonia.

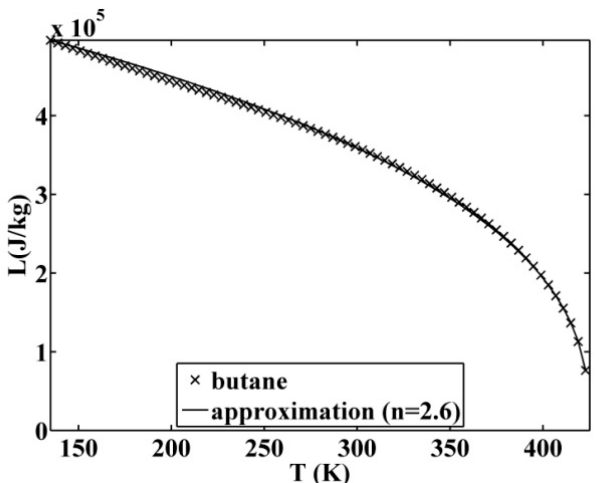

(a)

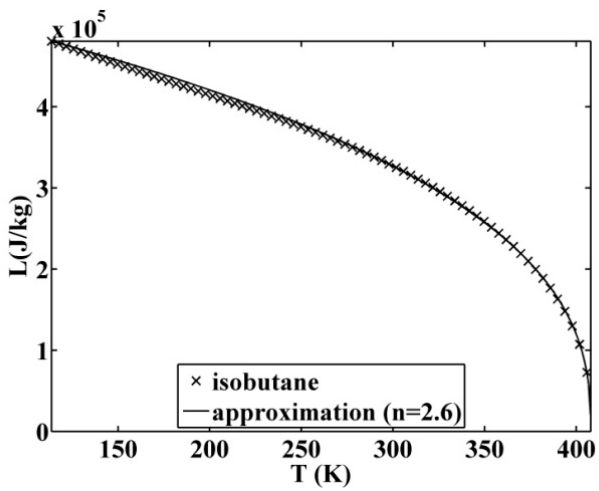

(b)

Figure 8. Cont. 


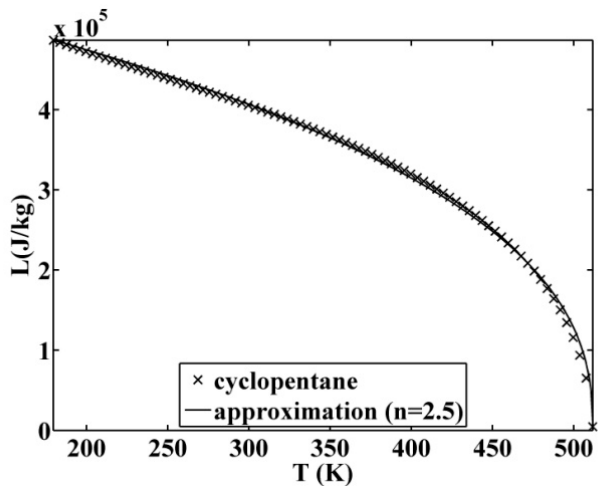

(c)

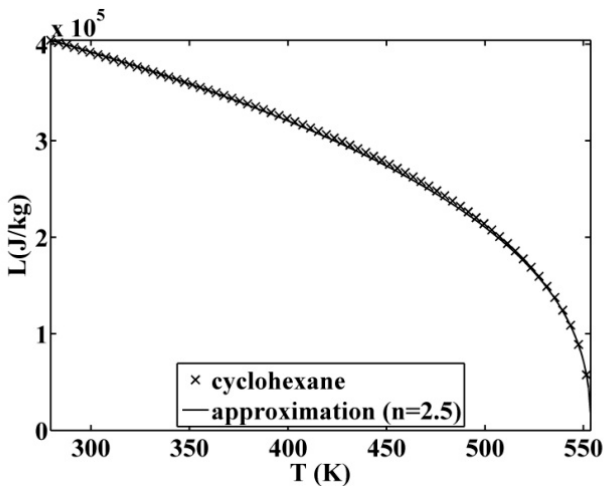

(d)

Figure 8. Approximated latent heat of vaporization for (a) butane; (b) isobutane; (c) cyclopentane; (d) cyclohexane.

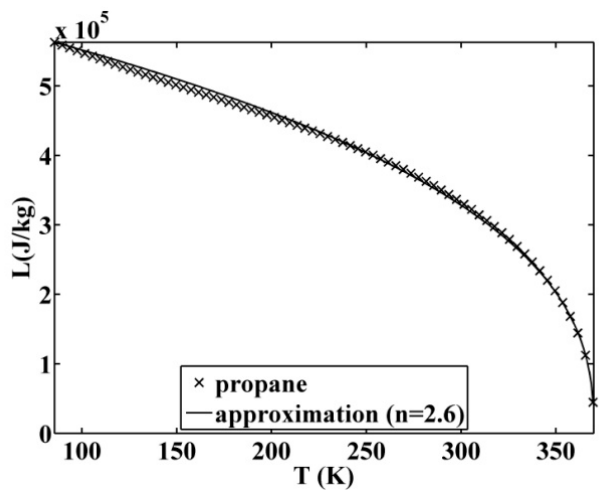

(a)

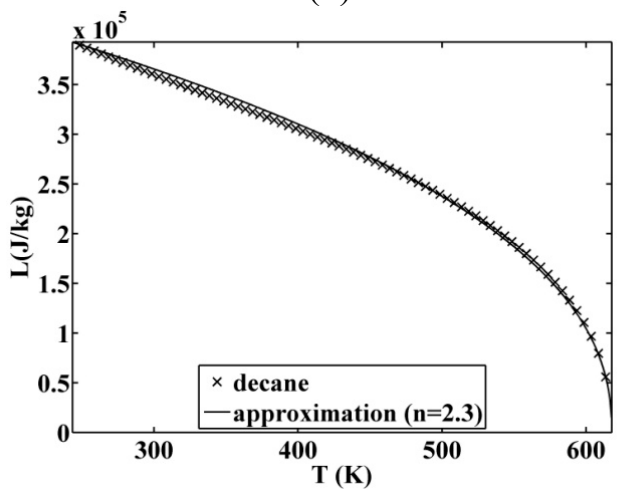

(c)

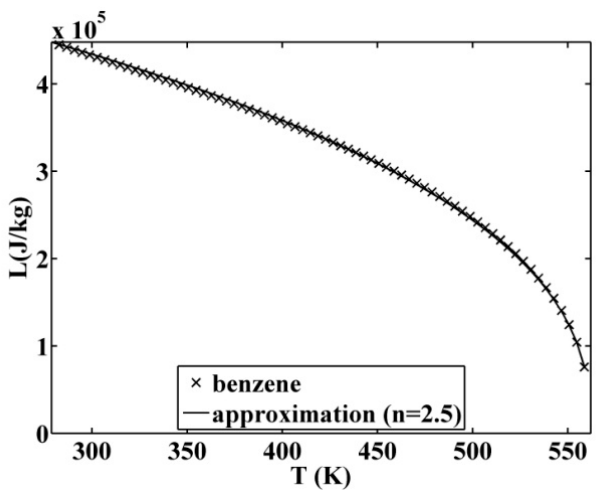

(b)

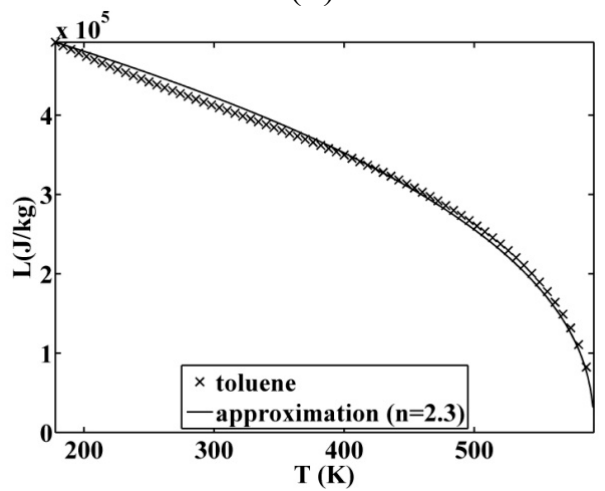

(d)

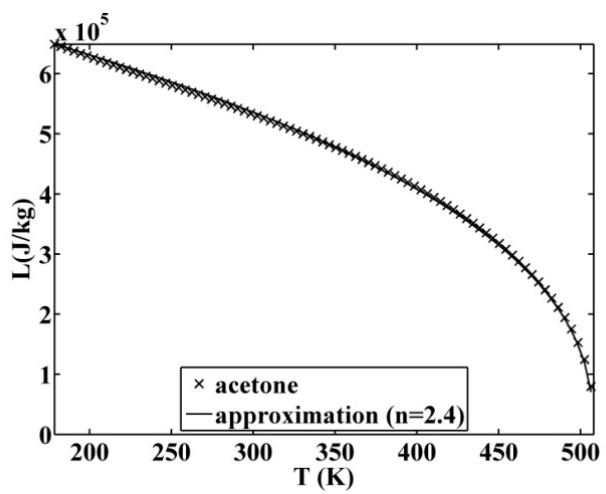

(e)

Figure 9. Approximated latent heat of vaporization for (a) propane; (b) benzene; (c) decane; (d) toluene; (e) acetone. 


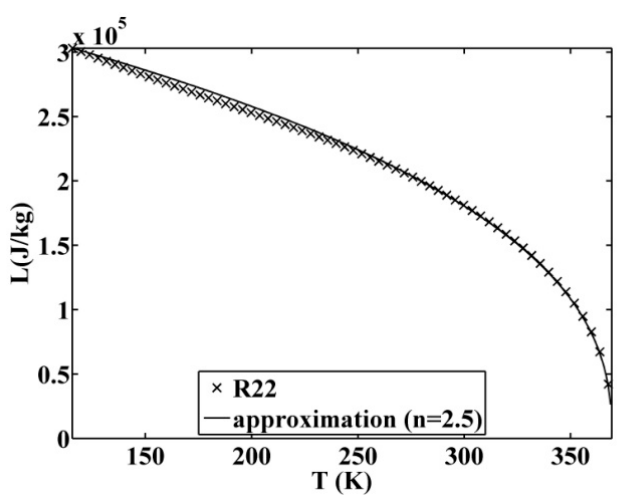

(a)

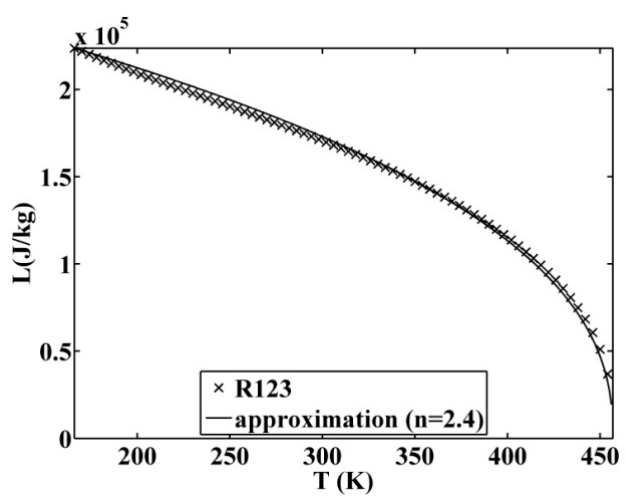

(b)

Figure 10. Approximated latent heat of vaporization for (a) R22 and (b) R123.

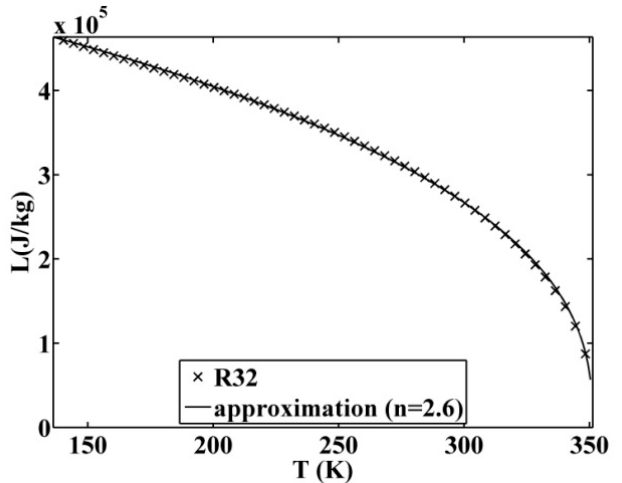

(a)

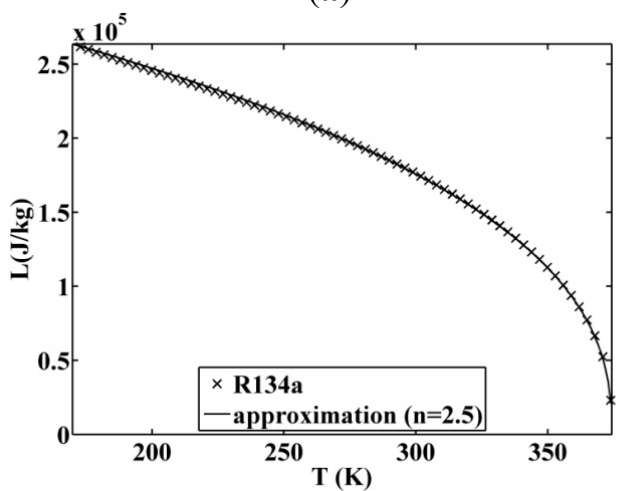

(c)

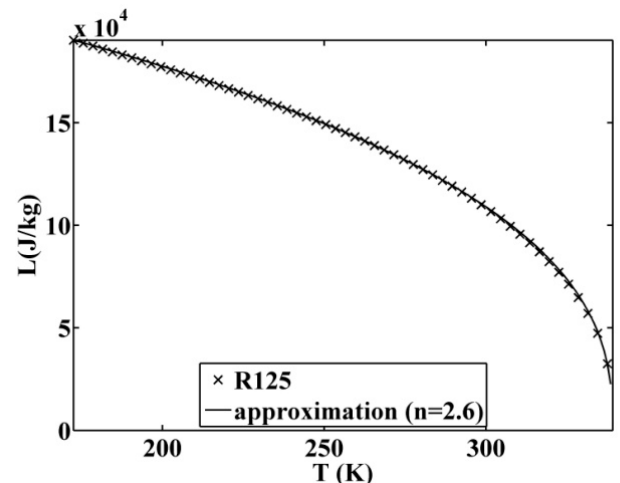

(b)

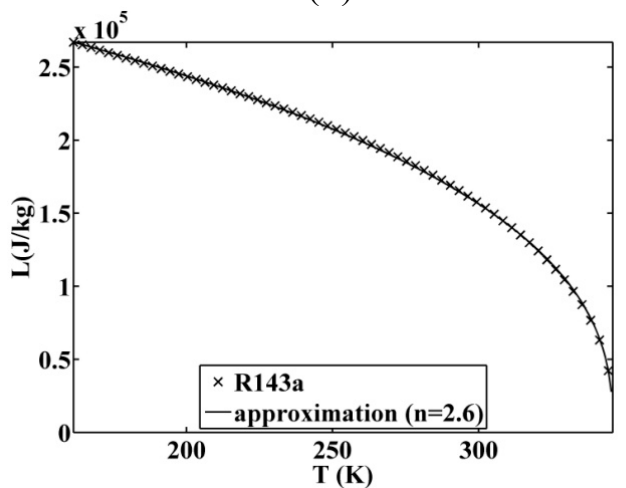

(d)

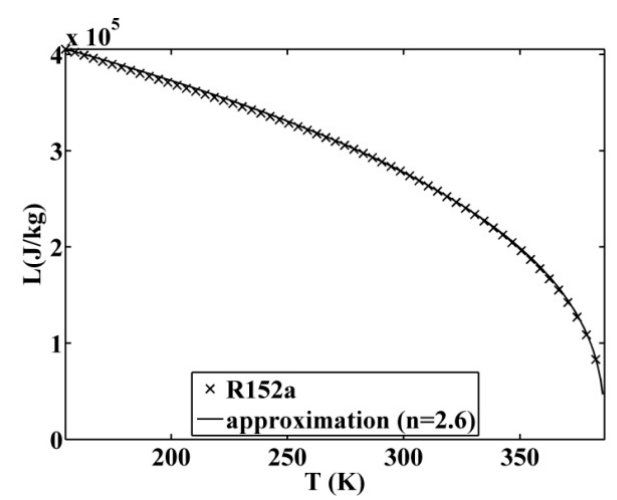

(e)

Figure 11. Approximated latent heat of vaporization for (a) R32; (b) R125; (c) R134a; (d) R143a; and (e) R152a. 


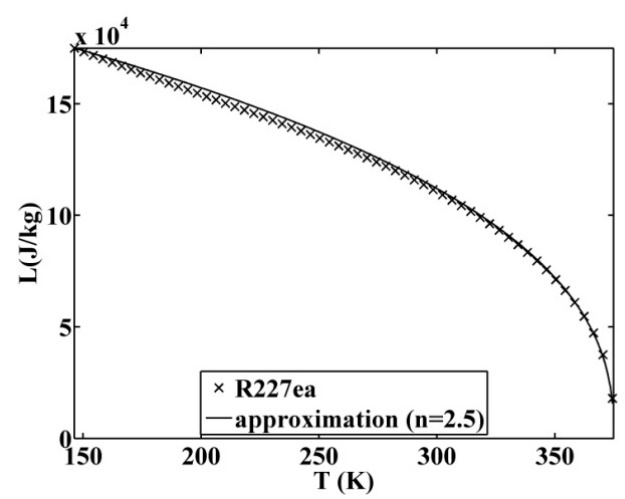

(a)

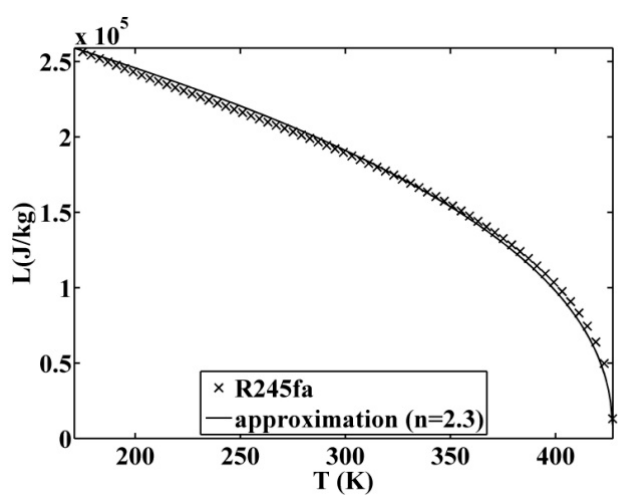

(b)

Figure 12. Approximated latent heat of vaporization for (a) R227ea and (b) $245 \mathrm{fa}$.

\subsection{Endogenous Optimization}

The entering heat rate depends on the latent heat of vaporization $L\left(T_{H}\right)$ :

$$
\dot{Q}_{H}=\dot{m} L\left(T_{H}\right)
$$

$\dot{m}$ is the cycled fluid mass flow rate.

The outgoing mechanical power can be expressed with (2) and (21) as:

$$
-\dot{W}=\dot{m} L\left(T_{H}\right)\left(1-\frac{T_{L}}{T_{H}}\right)
$$

To maximize the outgoing mechanical power we have to solve:

$$
\left.\frac{\partial(-\dot{W})}{\partial T_{H}}\right|_{\dot{m}}=0
$$

The optimal high temperature, taking Equation (19) into account, is:

$$
T_{H_{\text {opt }}}^{\text {endo }}=\frac{1}{2} T_{L}\left(\sqrt{(n-1)^{2}+4 n \frac{T_{C}}{T_{L}}}-(n-1)\right)
$$

$n$ depends on the fluid and is between 2 and 3. $T_{C}$ is the critical temperature of the considered fluid and $T_{L}$ is assumed to be known. The result means that, for a given fluid, we know at which temperature the fluid must be evaporated to deliver the maximum power for an endoreversible cycle and a fixed condensation temperature. To view this result, the variation of the area of the cycle versus the evaporation temperature is shown in Figure 13 for a wet fluid. In Figure 13a, this area is represented in the entropy diagram. In Figure $13 \mathrm{~b}$, the area is directly plotted versus temperature $T_{H}$. For $T_{H}=T_{L}$ or for $T_{H}=T_{C}$, the area is null. The optimal temperature is the temperature at maximal power output, which is equivalent to the maximum area. It is also valid for dry and isentropic fluids because it is only the vaporization which fixes the length of the rectangle. The height of the rectangle depends on the temperature difference. The optimization corresponds to the optimal allocation of both sides to maximize the surface area of the rectangle. Recalled that the low temperature is fixed. 


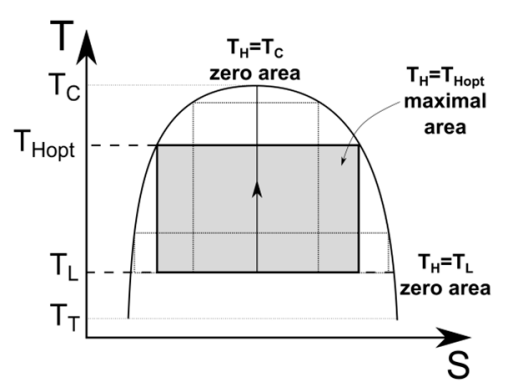

(a)

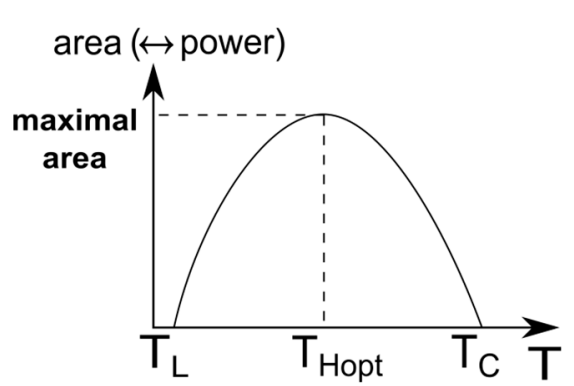

(b)

Figure 13. Specific work variation with the high temperature (a) representation in the entropy diagram; (b) corresponding behavior.

The maximum power output is:

$$
-\dot{W}^{\text {endo }}=\dot{m} L_{T_{T}}\left(\frac{T_{C}-T_{H_{o p t}}^{\text {endo }}}{T_{C}-T_{T}}\right)^{\frac{1}{n}}\left(1-\frac{T_{L}}{T_{H_{o p t}}^{\text {endo }}}\right)
$$

The entering heat rate becomes:

$$
\dot{Q}_{H}^{e n d o}=\dot{m} L_{T_{T}}\left(\frac{T_{C}-T_{H_{o p t}}^{e n d o}}{T_{C}-T_{T}}\right)^{\frac{1}{n}}
$$

The outgoing heat rate is:

$$
\dot{Q}_{L}^{e n d o}=-\dot{m} L_{T_{T}} \frac{T_{L}}{T_{H_{o p t}}^{e n d o}}\left(\frac{T_{C}-T_{H_{o p t}}^{e n d o}}{T_{C}-T_{T}}\right)^{\frac{1}{n}}
$$

\subsubsection{Temperature $T_{L}$ Equal to the Ambient Temperature $T_{0}$}

For the first case studied, the low temperature $T_{L}$ is fixed and equal to the ambient one $T_{0}$. The variation of the optimal dimensionless temperature $t_{h_{\text {opt }}}^{\text {endo }}=T_{H_{o p t}}^{\text {endo }} / T_{0}$ with the increase of the critical dimensionless temperature $t_{c}=T_{C} / T_{0}$ is plotted in Figure 14 for different fluids. The vaporization temperature and the corresponding compression ratio for the fluid selection are listed in Table 2. Note that the condensation pressure at atmospheric temperature is very low for some fluids $\left(P_{L}<5 \times 10^{3} \mathrm{~Pa}\right.$ for water, decane and toluene), and quite low for acetone, cyclopentane, cyclohexane and benzene $\left(P_{L}<5 \times 10^{4} \mathrm{~Pa}\right)$. This makes the implementation difficult because compression ratios are not physically acceptable. Moreover, for some fluids (R125, R134a, R32, R22, propane, R134a, $\mathrm{R} 152$, and ammonia) the low pressure is higher than $5 \times 10^{5} \mathrm{~Pa}$. This situation is not an ideal one because it induces high evaporation pressure, which imposes some technological constraints (principally the choice of exchanger and the maintenance cost). 


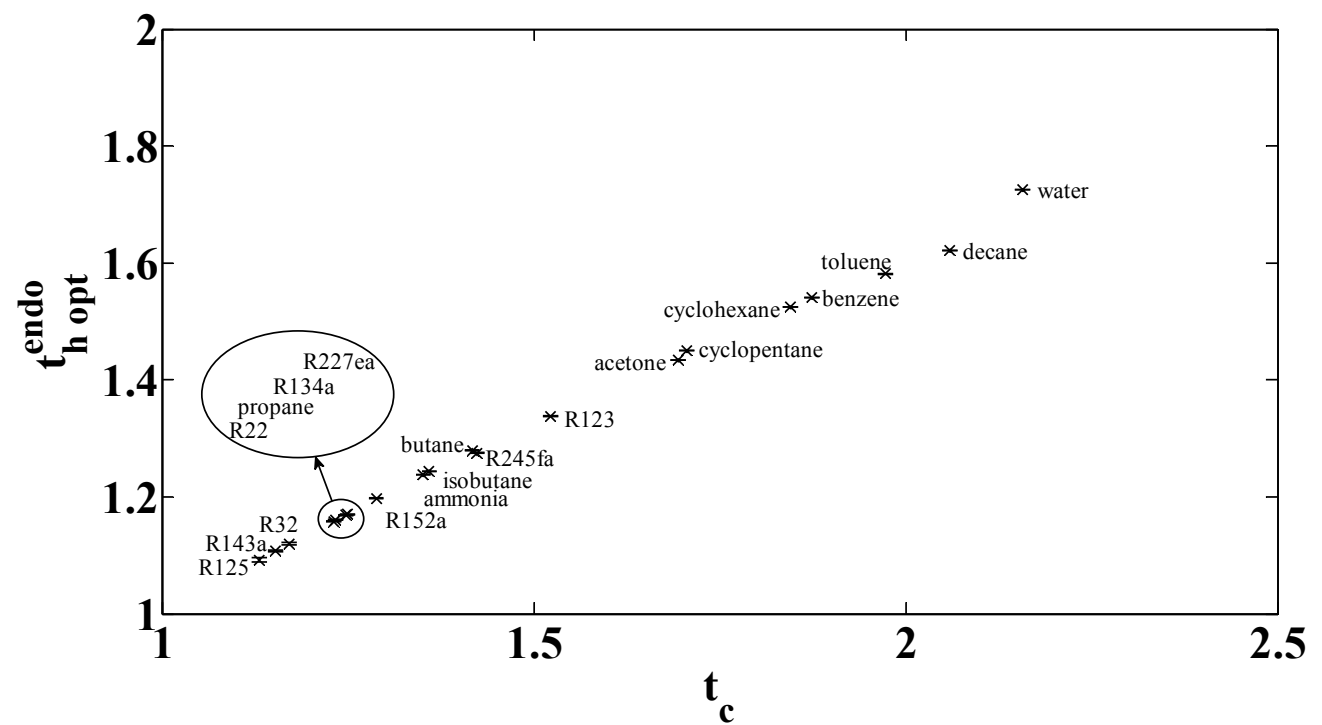

Figure 14. Optimal high temperature for variable critical temperature with $T_{L}=300 \mathrm{~K}$.

Table 2. Optimal vaporization temperature and corresponding compression ratio for fluid selection.

\begin{tabular}{|c|c|c|c|c|c|c|c|c|c|c|}
\hline \multirow{2}{*}{ Substance } & \multicolumn{5}{|c|}{$T_{L}$ imposed at $300 \mathrm{~K}$} & \multicolumn{5}{|c|}{$P_{L}$ imposed at $1 \times 10^{5} \mathrm{~Pa}$} \\
\hline & $T_{L}\left(=T_{0}\right)$ & $P_{L}$ & $T_{H_{\text {opt }}}^{\text {endo }}$ & $P_{H}$ & $\boldsymbol{\tau}$ & $T_{L}$ & $P_{L}\left(=P_{0}\right)$ & $T_{H_{\text {opt }}}^{\text {endo }}$ & $P_{H}$ & $\tau$ \\
\hline $\mathrm{R} 125$ & 300 & $1.45 \times 10^{6}$ & $327 \pm 2$ & $2.80 \times 10^{6}$ & 1.9 & 225 & $1 \times 10^{5}$ & $300 \pm 1$ & $1.46 \times 10^{6}$ & 15 \\
\hline $\mathrm{R} 143 \mathrm{a}$ & 300 & $1.32 \times 10^{6}$ & $332 \pm 1$ & $2.81 \times 10^{6}$ & 2.1 & 226 & $1 \times 10^{5}$ & $305 \pm 1$ & $1.49 \times 10^{6}$ & 15 \\
\hline $\mathrm{R} 32$ & 300 & $1.77 \times 10^{6}$ & $335 \pm 1$ & $4.17 \times 10^{6}$ & 2.4 & 221 & $1 \times 10^{5}$ & $306 \pm 1$ & $2.08 \times 10^{6}$ & 21 \\
\hline $\mathrm{R} 22$ & 300 & $1.10 \times 10^{6}$ & $347 \pm 1$ & $3.27 \times 10^{6}$ & 3 & 232 & $1 \times 10^{5}$ & $320 \pm 1$ & $1.83 \times 10^{6}$ & 18 \\
\hline propane & 300 & $9.98 \times 10^{5}$ & $348 \pm 1$ & $2.86 \times 10^{6}$ & 2.9 & 231 & $1 \times 10^{5}$ & $321 \pm 1$ & $1.65 \times 10^{6}$ & 16 \\
\hline $\mathrm{R} 134 \mathrm{a}$ & 300 & $7.03 \times 10^{5}$ & $351 \pm 1$ & $2.49 \times 10^{6}$ & 3.6 & 247 & $1 \times 10^{5}$ & $330 \pm 1$ & $1.55 \times 10^{6}$ & 16 \\
\hline R227ea & 300 & $4.81 \times 10^{5}$ & $351 \pm 1$ & $1.77 \times 10^{6}$ & 3.7 & 257 & $1 \times 10^{5}$ & $334 \pm 1$ & $1.21 \times 10^{6}$ & 12 \\
\hline $\mathrm{R} 152 \mathrm{a}$ & 300 & $6.30 \times 10^{5}$ & $358 \pm 1$ & $2.65 \times 10^{6}$ & 4.2 & 249 & $1 \times 10^{5}$ & $339 \pm 1$ & $1.72 \times 10^{6}$ & 17 \\
\hline ammonia & 300 & $1.06 \times 10^{6}$ & $371 \pm 1$ & $6.04 \times 10^{6}$ & 5.7 & 240 & $1 \times 10^{5}$ & $346 \pm 1$ & $3.55 \times 10^{6}$ & 35 \\
\hline isobutane & 300 & $3.70 \times 10^{5}$ & $372 \pm 1$ & $1.98 \times 10^{6}$ & 5.4 & 261 & $1 \times 10^{5}$ & $357 \pm 1$ & $1.46 \times 10^{6}$ & 15 \\
\hline butane & 300 & $2.58 \times 10^{5}$ & $383 \pm 1$ & $1.87 \times 10^{6}$ & 7.3 & 272 & $1 \times 10^{5}$ & $372 \pm 1$ & $1.51 \times 10^{6}$ & 15 \\
\hline R245fa & 300 & $1.59 \times 10^{5}$ & $382 \pm 1$ & $1.55 \times 10^{6}$ & 10 & 288 & $1 \times 10^{5}$ & $377 \pm 1$ & $1.39 \times 10^{6}$ & 14 \\
\hline R123 & 300 & $9.78 \times 10^{4}$ & $401 \pm 1$ & $1.41 \times 10^{6}$ & 14 & 301 & $1 \times 10^{5}$ & $401 \pm 1$ & $1.42 \times 10^{6}$ & 14 \\
\hline acetone & 300 & $3.33 \times 10^{4}$ & $432 \pm 1$ & $1.31 \times 10^{6}$ & 39 & 329 & $1 \times 10^{5}$ & $444 \pm 1$ & $1.68 \times 10^{6}$ & 17 \\
\hline cyclopentane & 300 & $4.55 \times 10^{4}$ & $434 \pm 1$ & $1.44 \times 10^{6}$ & 32 & 322 & $1 \times 10^{5}$ & $444 \pm 1$ & $1.71 \times 10^{6}$ & 17 \\
\hline cyclohexane & 300 & $1.41 \times 10^{4}$ & $458 \pm 1$ & $1.04 \times 10^{6}$ & 74 & 353 & $1 \times 10^{5}$ & $483 \pm 1$ & $1.56 \times 10^{6}$ & 16 \\
\hline benzene & 300 & $1.38 \times 10^{4}$ & $462 \pm 1$ & $1.20 \times 10^{6}$ & 87 & 353 & $1 \times 10^{5}$ & $488 \pm 1$ & $1.80 \times 10^{6}$ & 18 \\
\hline toluene & 300 & $4.18 \times 10^{3}$ & $473 \pm 1$ & $7.67 \times 10^{6}$ & 184 & 383 & $1 \times 10^{5}$ & $515 \pm 1$ & $1.50 \times 10^{6}$ & 15 \\
\hline decane & 300 & $2.07 \times 10^{2}$ & $492 \pm 1$ & $2.49 \times 10^{6}$ & 1202 & 447 & $1 \times 10^{5}$ & $558 \pm 1$ & $8.90 \times 10^{6}$ & 8.9 \\
\hline water & 300 & $3.54 \times 10^{3}$ & $507 \pm 1$ & $3.62 \times 10^{6}$ & 1023 & 373 & $1 \times 10^{5}$ & $554 \pm 1$ & $6.51 \times 10^{6}$ & 65 \\
\hline
\end{tabular}

3.2.2. Pressure $P_{L}$ Equal to the Ambient Pressure $P_{0}$

A second optimization is possible. The low pressure is fixed to the atmospheric pressure $P_{0}$ and the low temperature is the temperature of condensation at the atmospheric pressure. $T_{L}$ is deduced from the 
nature of the fluid (especial temperature of vaporization at ambient pressure). The optimal results are given in Figure 15 and Table 2. The condensation temperature under these conditions is equal to $T_{0}$ for R123, both hypotheses are equivalent for this fluid. For a large range of selected fluids, the low temperature is lower than the ambient one (R125, R143a, R32, R22, propane, R134a, R227ea, R152a, ammonia, isobutene, butane, and R245fa). That is not physically acceptable. A compromise between low temperature and low pressure is necessary for getting physically and technologically realistic conditions. This compromise depends on the selected fluid.

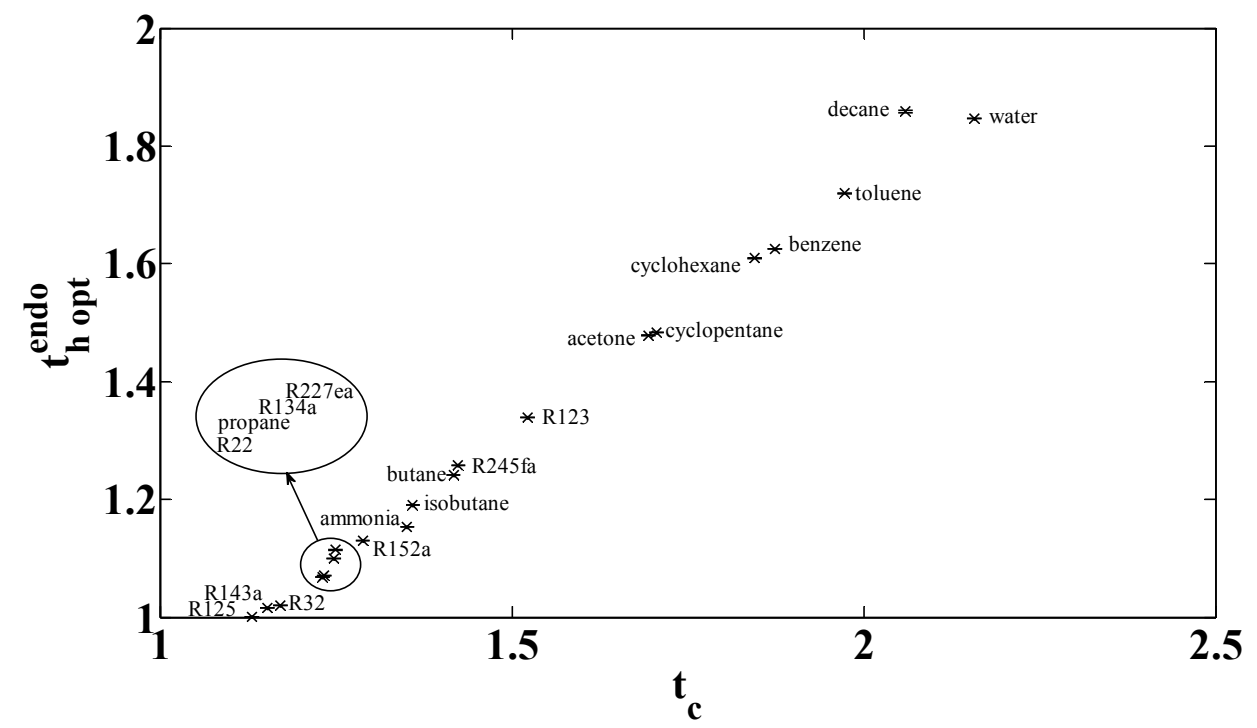

Figure 15. Optimal high temperature for variable critical temperature with $P_{L}=1.0 \times 10^{5} \mathrm{~Pa}$.

\section{Endogenous and Exogenous Optimization of a Carnot Engine}

The external fluid is considered as a limiting factor so the energy balances are the same as with the exogenous case (Equations (5) and (6)). The Objective Function $(O F)$ to maximize is the mechanical power is:

$$
O F=-\dot{W}=\dot{C}_{H}\left(T_{H S i}-T_{H}\right)\left(1-\frac{T_{L}}{T_{H}}\right)
$$

There is a supplementary constraint $C$ on the mass flow rate. The heat rate transferred by the heat source to the cycled fluid is the energy of vaporization. Equations (5) and (21) are equals:

$$
C=\dot{C}_{H}\left(T_{H S i}-T_{H}\right)-\dot{m} L\left(T_{H}\right)=0
$$

$L\left(T_{H}\right)$ can be replaced by its value (Equation (19)). The system has an optimum, which maximizes the mechanical power output for the variables $T_{H}$ and $\dot{m}$. The Lagrangien $\left(L_{g}\right)$ is:

$$
L_{g}=O F+\lambda C=\dot{C}_{H}\left(T_{H S i}-T_{H}\right)\left(1-\frac{T_{L}}{T_{H}}\right)+\lambda\left[\dot{C}_{H}\left(T_{H S i}-T_{H}\right)-\dot{m} L\left(T_{H}\right)\right]
$$

The system to solve is: 


$$
\left\{\begin{array}{l}
\frac{\partial L}{\partial \lambda}=0 \\
\frac{\partial L}{\partial T_{H}}=0 \\
\frac{\partial L}{\partial \dot{m}}=0
\end{array}\right.
$$

The optimal solutions are:

$$
\left\{\begin{array}{c}
T_{H_{\text {opt }}}=\sqrt{T_{H S i} T_{L}} \\
\dot{m}_{\text {opt }}=\frac{\dot{C}_{H} \sqrt{T_{H S i}}\left(\sqrt{T_{H S i}}-\sqrt{T_{L}}\right)}{L_{T_{T}}}\left(\frac{\left(T_{C}-\sqrt{T_{H S i} T_{L}}\right)}{T_{C}-T_{T}}\right)^{-\frac{1}{n}}
\end{array}\right.
$$

The dimensionless mass flow rate $m_{r_{o p t}}$ is:

$$
m_{r_{o p t}}=\frac{\dot{m}_{o p t} L_{T_{T}}}{T_{0} \dot{C}_{H}}=\frac{\sqrt{T_{H S i}}\left(\sqrt{T_{H S i}}-\sqrt{T_{L}}\right)}{T_{0}}\left(\frac{\left(T_{C}-\sqrt{T_{H S i} T_{L}}\right)}{T_{C}-T_{T}}\right)^{-\frac{1}{n}}
$$

Recall that the assumption of an ideal exchanger is made, it means that the exchange area is infinite. This assumption affects the optimal mass flow rate.

The dimensionless high temperature $t_{\text {hopt }}$ is:

$$
t_{\text {hopt }}=\frac{T_{H_{o p t}}}{T_{0}}=\frac{\sqrt{T_{H S i} T_{L}}}{T_{0}}
$$

The corresponding maximal power output, the entering heat rate, and the outgoing heat rate are the same as the exogenous optimization (Equations (8)-(10)). Coupling the endogenous and exogenous equation permits to add a constraint to optimize the mass flow rate of the cycled fluid.

To have the better fluid for a given heat source, we seek to determine the optimal critical temperature depending on the entering heat source temperature. For this, the optimization results are equalized to those of the endogenous optimization. Indeed, the high temperature must satisfy:

$$
T_{H_{o p t}}=T_{H_{o p t}}^{\text {endo }}
$$

To satisfy (35), the heat source temperature $T_{H S i}$ and the critical temperature of the working fluid $T_{C}$ are linked by the relation:

$$
T_{C}=\frac{\sqrt{T_{H S i}}}{n}\left(\sqrt{T_{L}}(n-1)+\sqrt{T_{H S i}}\right)
$$

This relation depends on the fluid. The dimensionless critical temperature is:

$$
t_{c}=\frac{T_{C}}{T_{0}}
$$

We can see in Figure 16a that the behavior of the dimensionless optimal critical temperature $t_{c}$ and the optimal high temperature of the cycled fluid $t_{\text {hopt }}$ for variable entering heat source temperature $t_{h s i}=T_{H S i} / T_{0}$, for different fluids and $T_{L}=300 \mathrm{~K}$. The corresponding dimensionless mass flow rate is 
given in Figure 16b. The corresponding values are listed in Table 3. For the case where $P_{L}$ is fixed to $1 \times 10^{5} \mathrm{~Pa}$, the behavior of the results are given in Figure $17 \mathrm{a}, \mathrm{b}$.

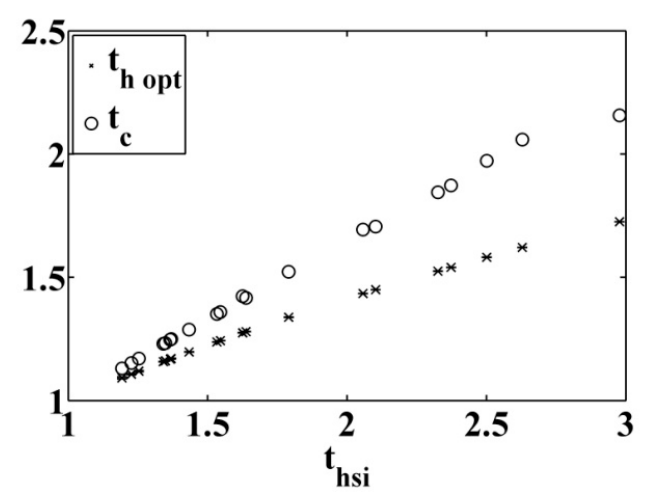

(a)

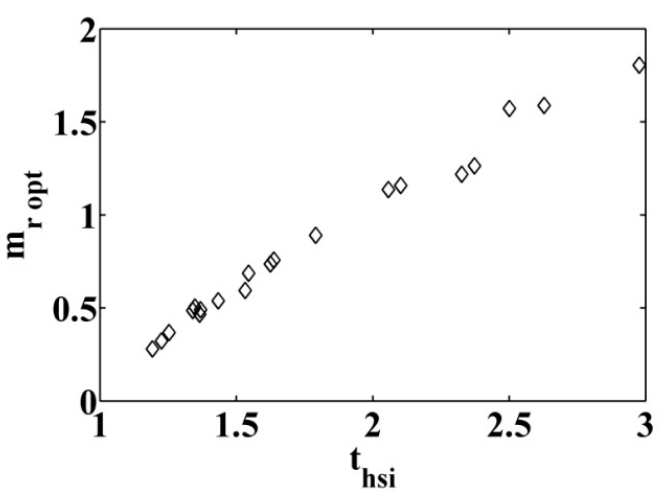

(b)

Figure 16. (a) Optimal critical temperature and optimal vaporization temperature; (b) internal mass flow rate; for entering heat source temperature variable and $T_{L}=300 \mathrm{~K}$.

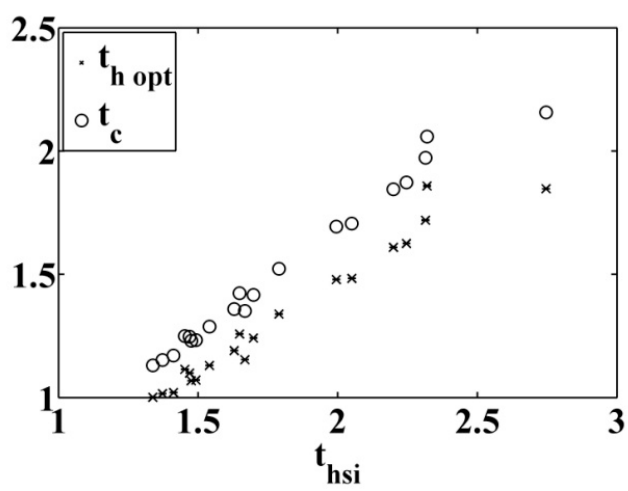

(a)

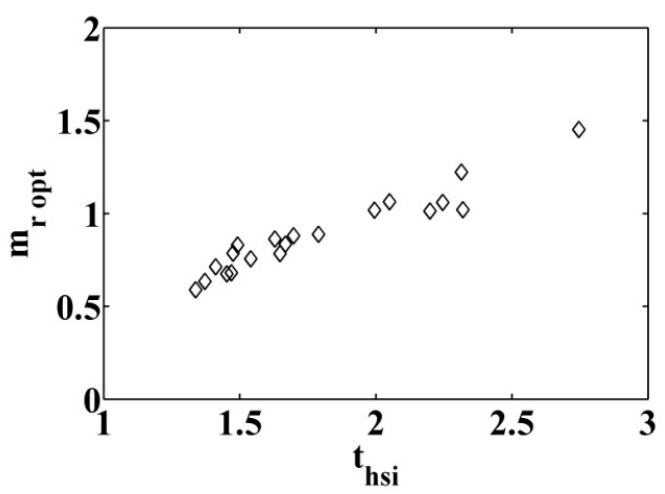

(b)

Figure 17. (a) Optimal critical temperature and optimal vaporization temperature; (b) internal mass flow rate; for entering heat source temperature variable and $P_{L}=1.0 \times 10^{5} \mathrm{~Pa}$.

Table 3. Optimal high temperature, heat source temperature and mass flow rate for different fluids.

\begin{tabular}{|c|c|c|c|c|c|c|}
\hline \multirow{2}{*}{ Substance } & \multicolumn{3}{|c|}{$T_{L}$ imposed at $300 \mathrm{~K}$} & \multicolumn{3}{|c|}{$P_{L}$ imposed at $1 \times 10^{5} \mathrm{~Pa}$} \\
\hline & $\boldsymbol{T}_{H_{o p t}}$ & $T_{H S i}$ & $m_{r_{o p t}}$ & $T_{H_{o p t}}$ & $T_{H S i}$ & $\boldsymbol{m}_{r_{o p t}}$ \\
\hline $\mathrm{R} 125$ & $327 \pm 2$ & 358 & 0.280 & $300 \pm 1$ & 401 & 0.589 \\
\hline $\mathrm{R} 143 \mathrm{a}$ & $332 \pm 1$ & 368 & 0.323 & $305 \pm 1$ & 412 & 0.635 \\
\hline R32 & $335 \pm 1$ & 376 & 0.368 & $306 \pm 1$ & 424 & 0.713 \\
\hline $\mathrm{R} 22$ & $347 \pm 1$ & 402 & 0.487 & $320 \pm 1$ & 443 & 0.786 \\
\hline propane & $348 \pm 1$ & 404 & 0.504 & $321 \pm 1$ & 448 & 0.830 \\
\hline $\mathrm{R} 134 \mathrm{a}$ & $351 \pm 1$ & 410 & 0.467 & $330 \pm 1$ & 441 & 0.681 \\
\hline R227ea & $351 \pm 1$ & 411 & 0.491 & $334 \pm 1$ & 436 & 0.675 \\
\hline $\mathrm{R} 152 \mathrm{a}$ & $358 \pm 1$ & 430 & 0.538 & $339 \pm 1$ & 462 & 0.756 \\
\hline ammonia & $371 \pm 1$ & 460 & 0.593 & $346 \pm 1$ & 500 & 0.835 \\
\hline isobutane & $372 \pm 1$ & 464 & 0.686 & $357 \pm 1$ & 489 & 0.863 \\
\hline
\end{tabular}


Table 3. Cont.

\begin{tabular}{|c|c|c|c|c|c|c|}
\hline \multirow{2}{*}{ Substance } & \multicolumn{3}{|c|}{$T_{L}$ imposed at $300 \mathrm{~K}$} & \multicolumn{3}{|c|}{$P_{L}$ imposed at $1 \times 10^{5} \mathrm{~Pa}$} \\
\hline & $T_{H_{o p t}}$ & $T_{H S i}$ & $\boldsymbol{m}_{r_{o p t}}$ & $T_{H_{o p t}}$ & $T_{H S i}$ & $m_{r_{o p t}}$ \\
\hline butane & $383 \pm 1$ & 491 & 0.757 & $372 \pm 1$ & 509 & 0.880 \\
\hline R245fa & $384 \pm 1$ & 488 & 0.736 & $377 \pm 1$ & 494 & 0.783 \\
\hline R123 & $402 \pm 1$ & 537 & 0.890 & $402 \pm 1$ & 537 & 0.888 \\
\hline acetone & $432 \pm 1$ & 617 & 1.14 & $444 \pm 1$ & 598 & 1.02 \\
\hline cyclopentane & $434 \pm 1$ & 628 & 1.16 & $445 \pm 1$ & 615 & 1.06 \\
\hline cyclohexane & $458 \pm 1$ & 698 & 1.22 & $483 \pm 1$ & 660 & 1.01 \\
\hline benzene & $462 \pm 1$ & 712 & 1.26 & $488 \pm 1$ & 674 & 1.06 \\
\hline toluene & $478 \pm 1$ & 750 & 1.57 & $516 \pm 1$ & 694 & 1.22 \\
\hline decane & $492 \pm 1$ & 788 & 1.59 & $558 \pm 1$ & 696 & 1.02 \\
\hline water & $507 \pm 1$ & 893 & 1.80 & $554 \pm 1$ & 824 & 1.45 \\
\hline
\end{tabular}

For example, for a heat source of $1 \mathrm{~kg} / \mathrm{s}$ of industrial flue gas at $410 \mathrm{~K}$, the calorific rate is equal to $1000 \mathrm{~W} / \mathrm{K}$. For a low temperature equal to the ambient temperature at $300 \mathrm{~K}$, the optimal high temperature is $351 \mathrm{~K}$. The corresponding fluid is the R134a. The optimal mass flow rate of internal fluid is $0.537 \mathrm{~kg} / \mathrm{s}$.

\section{Conclusion}

A Carnot type engine is modeled and optimized. The heating corresponds to the vaporization of the internal working fluid and the cooling of the condensation. The temperature of condensation is supposed known and the internal dissipations (entropy production) are neglected. A known optimization of a Carnot engine with the Chambadal model is recovered and completed by an endogenous optimization. This second optimization takes into account the working fluid and the behavior of its latent heat of vaporization. Making these two optima equal allows linking the heat source to the internal cycle. For a given temperature, mass flow rate, and composition of the waste heat to recover, an optimal fluid and its temperature of vaporization is proposed. The optimal conditions size also the internal mass flow rate and the compression ratio (pump size). The optimum corresponds to the maximum of power output, and must be combined with the environmental fluid impact and the technological constraints. These results have been proposed for pure fluids. Extension to mixtures is envisioned.

\section{Acknowledgments}

I thank the company Hevatech (Malataverne, France) and the Agence de l'environnement et de la maîtrise de l'énergie (ADEME, Angers, France).

\section{Author Contributions}

Michel Feidt designed and supervised the research. Denis Maillet oversaw and improved the approach. Mathilde Blaise developed the calculations, plotted the results and wrote the article. All authors have read and approved the final manuscript. 


\section{Conflicts of Interest}

The authors declare no conflicts of interest.

\section{References}

1. Carnot, S. Réflexions sur la puissance motrice du feu et sur les machines propres à développer cette puissance; Bachelier: Paris, France, 1824. (in French)

2. Curzon, F.L.; Ahlborn, B. Efficiency of a Carnot engine at maximum power output. Am. J. Phys. 1975, 1, 22-24.

3. Novikov, I. The efficiency of atomic power stations (a review). J. Nucl. Energy 1958, 7, $125-128$.

4. Chambadal, P. Le choix du cycle thermique dans une usine génératrice nucléaire. Revue Générale de l'Electricité 1958, 67, 332-345. (in French)

5. Vaudrey, A.; Lanzetta, F.; Feidt, M.H.B. Reitlinger and the origins of the efficiency at maximum power formula for heat engines. J. Non-equilib. Thermodyn. 2014, 39, 199-203.

6. Moreau, M.; Gaveau, B.; Schuman, S. Stochastic dynamics, efficiency and sustainable power production. Eur. Phys. J. D 2011, 62, 67-71.

7. Yvon, J. The Saclay reactor: Two years experience on heat transfer by means of compressed gas. In Proceedings of the International Conference on Peaceful Uses of Atomic Energy, Geneva, Switzerland, 8-20 August 1955.

8. Andresen, B. Finite-Time Thermodynamics; Physics Laboratory II, University of Copenhague: Copenhague, Denmark, 1983.

9. Feidt, M.; Costea, M.; Petre, C.; Petrescu, S. Optimization of the direct Carnot cycle. Appl. Therm. Eng. 2007, 27, 829-839.

10. Chen, J.; Yan, Z.; Lin, G.; Andresen, B. On the Curzon-Ahlborn efficiency and its connection with the efficiencies of real heat engines. Energy Convers. Manag. 2001, 42, 173-181.

11. Kodal, A.; Sahin, B.; Yilmaz, T. A comparative performance analysis of irreversible Carnot heat engines under maximum power density and maximum power conditions. Energy Convers. Manag. 2000, 41, 235-248.

12. Agnew, B.; Anderson, A.; Forst, T.H. Optimization of a steady state flow Carnot cycle with external irreversibilities for maximum specific output. Appl. Therm. Eng. 1997, 17, 3-15.

13. Feidt, M. Thermodynamique Optimale en Dimensions Physiques Finies; Lavoisier: Paris, France, 2013.

14. Tchanche, B.F.; Papadakis, G.; Lambrinos, G.; Frangoudakis, A. Fluid selection for a low-temperature solar organic Rankine cycle. Appl. Therm. Eng. 2009, 29, 2468-2476.

15. Chen, H.; Goswami, D.Y.; Stefanakos, E.K. A review of thermodynamic cycles and working fluids for the conversion of low-grade heat. Renew. Sustain. Energy Rev. 2010, 14, 3059-3067.

16. Hung, T.C.; Wang, S.K.; Kuo, C.H.; Pei, B.S.; Tsai, K.F. A study of organic working fluids on system efficiency of an ORC using low-grade energy sources. Energy 2010, 35, 1403-1411.

17. Badr, O.; Probert, S.D.; O'Callaghan, P.W. Selecting a working fluid for a Rankine-cycle engine, Appl. Energy 1985, 21, 1-42. 
18. Liu, B.-T.; Chien, K.-H.; Wang, C.C. Effect of working fluids on organic Rankine cycle for waste heat recovery. Energy 2004, 29, 1207-1217.

19. West, H.H.; Patton, J.M. Selection of working fluids for the organic Rankine cycle. In Proceedings of the First Industrial Energy Technology Conference, Houston, TX, USA, 22-25 April 1979; pp. 953-959.

20. Le, V.L.; Feidt, M.; Kheiri, A.; Pelloux-Prayer S. Performance optimization of low-temperature power generation by supercritical ORCs (Organic Rankine Cycles) using low GWP (Global Warming Potential) working fluids. Energy 2014, 67, 513-26.

21. De Witt, B.; Hugo, R. Naturally-Forced Slug Flow Expander for Application in a Waste-Heat Recovery Cycle. Energies 2014, 7, 7223-7244.

(C) 2015 by the authors; licensee MDPI, Basel, Switzerland. This article is an open access article distributed under the terms and conditions of the Creative Commons Attribution license (http://creativecommons.org/licenses/by/4.0/). 